http://dx.doi.org/10.5007/2175-7968.2014v1n33p261

\title{
OS SIMPSONS EM HAMLET: UM PETISCO DE SHAKESPEARE
}

\author{
Robert Salem* \\ Universidade Federal da Bahia
}

\begin{abstract}
Resumo: Este artigo se propõe a refletir sobre a adaptação de Hamlet em Os Simpsons no episódio Do the bard, man, a fim de observar aspectos importantes dessa recriação contemporânea. A releitura de Hamlet apresentada em Os Simpsons é uma peça dentro de outra, em que os personagens do seriado assumem os papéis dos personagens de Shakespeare. O artigo enfatiza a inclusão de tantos elementos da peça de Shakespeare em uma adaptação de apenas cinco minutos e sugere uma solução de storyboard para incluir aspectos dos famosos solilóquios.
\end{abstract}

Palavras-chave: Hamlet. Os Simpsons. Shakespeare. Adaptação. Tradução.

\section{THE SIMPSONS IN HAMLET: A TASTE OF SHAKESPEARE}

\begin{abstract}
This article proposes to reflect on the adaptation of Hamlet by The Simpsons in the episode Do the bard man, with the aim of observing important aspects of this contemporary recreation. The reframing of Hamlet in The Simpsons presents a play-within-a-play where the series' characters act out the roles of Shakespeare's characters. The inclusion of so many elements from Shakespeare's play in a five-minute adaptation is emphasized and a storyboard is suggested to include aspects of the famous soliloquies.
\end{abstract}

Keywords: Hamlet. The Simpsons. Shakespeare. Adaptation. Translation.

\footnotetext{
* Mestrado em Letras e Linguística pela Universidade Federal da Bahia (UFBA2010). Universidade Federal da Bahia, Salvador, Bahia, Brasil. E-email: bobsal65@ig.com.br
} 
Shakespeare escreveu a peça Hamlet, Prince of Denmark, entre 1601 e 1602, nos últimos anos da rainha Elizabeth I, que governou a Inglaterra de 1558 até a sua morte, em 1603 . Esta época, conhecida como a Idade de Ouro da história inglesa, evidenciou o surgimento da Inglaterra como uma potência europeia e presenciou um extraordinário florescimento cultural, especialmente nas áreas da língua e da literatura. Destacaram-se as obras dramáticas e poéticas de Shakespeare, que, além de influenciarem profundamente a cultura anglo-saxônica e ocidental, em geral, transformariam a língua inglesa. O período foi também marcado por muita violência, com uma série de guerras dinásticas, religiosas (entre católicos e protestantes) e lutas constantes na busca de poder imperial e comercial, especialmente entre a Inglaterra emergente e a Espanha preeminente.

Hamlet, indiscutivelmente a peça mais famosa do teatro dramático mundial, é a obra dramática mais extensa de Shakespeare, com uma duração que pode chegar a quase quatro horas no palco, a depender da edição usada. É uma peça densa, introspectiva, que trata de assassinato, suicídio, decepção, loucura e identidade, de uma maneira extremamente séria. A história é de um príncipe na Dinamarca medieval, Hamlet, que não aceita a morte do rei, seu pai e, em seguida, a aproximação de sua mãe com o tio Claudius. Sua vida começa a tornar-se insuportável quando o fantasma do pai lhe aparece à noite, no alto do castelo de Elsinore, na Dinamarca, contando que havia sido o próprio tio Claudius que matara o rei para apoderar-se do trono e casar-se com a rainha Gertrudes. Desde então, Hamlet resolve que precisa reparar tamanha injustiça e sente-se um homem imbuído com a missão de vingança. A esta causa, e com grande introspecção, ele dedica todos os seus esforços, com consequências trágicas para todos os personagens principais da peça.

Contada desta forma, e por quaisquer outros critérios exceto sua fama, a peça não parece, à primeira vista, conter um material ideal para ser tratada de modo cômico, satírico, típico dos escrito- 
res de The Simpsons. Realmente, o próprio Bart Simpson comenta, no fim do episódio, no vídeo, que a peça é enfadonha, apesar de mostrar tantas mortes. Mas a adaptação foi feita e televisada pela primeira vez nos Estados Unidos, em 17 de março de 2002, como parte do décimo quarto episódio da décima terceira temporada: Tales from the Public Domain (Contos de domínio público). $\mathrm{O}$ episódio contém três histórias: A Odisseia, Joana d'Arc. e, por último, Do the bard, man, que, se não é a única versão animada de Hamlet, pode ser considerada, com certeza, como a mais engraçada e, provavelmente, a mais curta, com uma duração de apenas cinco minutos e trinta segundos.

O episódio foi escrito e exibido numa época violenta, o começo do século XXI, apenas alguns meses depois do atentado do World Trade Center e da ocupação aliada do Afeganistão. O espectro da morte andava rondando por perto. Mas, independente do contexto social e político que estavam vivendo os EUA, a série animada The Simpsons já tinha mudado a história dos seriados televisivos norte-americanos com sua forma irreverente e cômica de apresentar a sociedade, fazendo rir, questionando e refletindo sobre questões sociais e valores provincianos, com um público-alvo de todas as idades e classes sociais. Em Hamlet, o episódio de The Simpsons tematizou um assunto sombrio, mas ficcional, dando-lhe o tratamento paródico habitual.

Conforme a crítica do século XX tem enfatizado, as obras tidas como 'canônicas' devem sua sobrevivência, pelo menos em parte, às recriações e adaptações feitas em tempos e lugares distantes daqueles dos textos-fonte e utilizando, frequentemente, outros sistemas semióticos. Ao mesmo tempo, as novas criações não podem ser consideradas inferiores às anteriores, mas olhadas como obras artísticas que possuem um valor próprio. Existe, porém, um sequenciamento natural das obras - as obras de partida são criadas e chegam a fazer parte do conhecimento coletivo universal, antes de outras, que lhes sucederão. É evidente, que esses textos sucessivos se relacionam entre si, de várias maneiras. Em termos de adapta- 
ção, Hutcheon (2006) resume bem a situação quando nos lembra que, do ponto de vista do adaptador, o processo de adaptar significa se apropriar ou salvar um texto existente, e isto sempre envolve uma interpretação e uma recriação.

No caso da adaptação de Hamlet para Do the bard, man, olhamos a recriação contemporânea com referência constante a seu texto de origem, pois é exatamente assim que faz a família Simpson, sentada na sua sala de televisão, quando o pai conta uma história bem conhecida do passado. Em outras palavras, este texto novo pretende representar seu texto de partida, mesmo sendo de modo condensado e com ênfase humorística. E é nesta representação, que se cumprirão os três papeis fundamentais da série de adaptações encenadas pelos Simpsons: o de divertir, o de informar e o de comentar.

Existe, ao mesmo tempo, uma grande diferença entre este tipo de adaptação e as transformações intersemióticas rotineiras. Tratando-se de uma obra considerada clássica, como Hamlet (e as mesmas considerações valeriam para a Odisseia de Homero, Don Quijote de Cervantes, e Robinson Crusoé de Defoe, por exemplo), determinar o que, efetivamente, constitui o seu texto de partida assume uma complexidade maior. Além do fato de não termos um texto definitivo da peça (a edição mais antiga é um terço menor do que a obra que se lê, hoje), tem que ser acrescida ao texto escrito ou impresso na época de Shakespeare, toda uma 'bagagem' acumulada sobre a peça e seus personagens, nos últimos séculos, no que ser refere à cultura popular e teatral. Logo, tudo isso faz parte da memória da obra deixada no imaginário dos povos. Muitos desses elementos são imagéticos e também artísticos, como gravuras, pinturas, citações, representações teatrais e tantos outros filmes gerados a partir do texto de partida. Juntos, todos esses signos remetem à imagem da obra Hamlet e tendem a ser levados automática e até subconscientemente em consideração pelos recriadores, em qualquer adaptação desse tipo, sobretudo se os adaptadores fazem parte da mesma cultura histórica da obra de partida. É este o caso de Do the bard, man de The Simpsons. 
É importante enfatizar que são precisamente esses acréscimos, ecos e transformações da peça de Shakespeare e do seu protagonista principal, na imaginação popular, que transformam a peça Hamlet em objeto interessante para ser representado àquela audiência de massa, público alvo de The Simpsons. Isso poderia acontecer com muito poucas outras obras de Shakespeare ou de seus contemporâneos, talvez apenas com Romeo and Juliet (c. 1595), por exatamente os mesmos motivos, quer dizer, pela sua presença no imaginário do povo, ao longo dos séculos; seria o caso, também, possivelmente, de Julius Caesar (1599), em consequência da sua base histórica, bem conhecida. Assim, Hamlet, o príncipe introvertido e violento, entra no rol de personagens como Robinson Crusoé, Gulliver, Don Quijote, Ali Babá e outros 'heróis' mundiais. E o ponto chave desta representação específica de The Simpsons é que será feita através de uma família comum da classe média baixa americana, com quem as massas podem facilmente se identificar.

Os personagens principais de The Simpsons são os cincos componentes da família Simpson: os pais Homer e Marge e os filhos Bart, Lisa e Maggie. Um número grande de personagens coadjuvantes, reconhecidos pela audiência do seriado, também povoam os episódios. Todos moram em Springfield, uma pequena cidade típica norte-americana, que é o ponto de partida das histórias.

A recriação de Hamlet apresentada em The Simpsons é uma peça dentro de outra peça, com os personagens da família e seus amigos assumindo os papeis dos personagens de Shakespeare. A história se desenvolve assim: depois de uma introdução do episódio, que ocorre na sala dos Simpsons, Bart, como o príncipe Hamlet, recebe a visita do Ghost (fantasma) do rei (Homer), que lhe pede que vingue a sua morte por envenenamento pelas mãos do irmão, o King (rei) atual, Claudius (Moe), que havia se casado com a Queen (rainha) Gertrude (Marge). Hamlet, com a ajuda de um Jester, (Bobo da corte, com Krusty vestido de palhaço), cria uma peça que faz com que o King demonstre a sua culpa ao assistir a encenação. Então, a namorada de Hamlet, Ophelia (Lisa), enlouquece e morre afoga- 
da. O King percebe que Hamlet havia descoberto tudo e pretende matá-lo. Mas Hamlet tenta matar o tio primeiro e, acidentalmente, mata Polonius (Chief Wiggum). O filho deste, Laertes (Ralph Wiggum), propõe um duelo com Hamlet para vingar a morte do pai. Bestamente, Laertes se mata e Hamlet consegue matar seu tio, o King. Os antigos amigos de Hamlet, agora inimigos, Rosencarl \& Guildenlenny (o Rosenkrantz e Guildenstern de Shakespeare, representados por Carl e Lenny) já tinham morrido envenenados. Hamlet sai para comemorar a nova situação, mas escorrega no sangue envenenado e morre. Quando a Queen chega e vê toda aquela confusão, aquela sujeira, ela se nega a limpar o recinto e se mata também, envenenada. Todos, enfim, morrem.

De volta à sala de televisão da casa da família, Bart comenta com Lisa e Homer, que achara a história chata, mesmo com tanta gente morrendo. Homer, ao contrário, elogia a história e informa, erradamente, que fora filmada como Ghostbusters (USA, 1994, diretor Ivan Reitman). O episódio termina com a família dançando ao som da música tema desse filme ${ }^{1}$.

A análise detalhada desta recriação revela uma busca, por parte dos criadores, de incluir, num roteiro intrinsecamente satírico e humorístico, uma profusão de elementos narrativos e dramáticos do texto de partida. A peça de Shakespeare, porém, é uma obra trágica, introvertida, reflexiva e, acima de tudo, adulta. É neste contexto que se explica, provavelmente, a omissão quase total de várias cenas e temas (os famosos conselhos de Polonius, por exemplo, e a relação amorosa entre Hamlet e Ophelia) e, em especial, dos quatro grandes solilóquios de Hamlet, que seriam difíceis de representar na sua recriação, ainda mais visualmente, devido à sua complexidade temática. Essa grande omissão é tão importante, que recebe um comentário dentro do próprio roteiro, quando, em certo momento, Bart, no papel de Hamlet, diz: You're not supposed to hear me - that's a soliloquy².

O título Do the bard, man não se refere diretamente à peça, apenas ao seu autor, Shakespeare, conhecido, muitas vezes nos países anglo-saxônicos, simplesmente pela expressão 'the Bard', sem 
a citação de qualquer nome próprio, em seguida. A palavra bard, hoje usada no sentido de poeta, foi cultivada pelos escritores Românticos do século XIX, e originalmente aplicada a poetas e músicos dos tempos antigos e medievais, que possuíam grande status na comunidade como criadores e por salvaguardar a poesia, bem como a historia oral do seu povo. Como não pode deixar de ser, em se tratando de The Simpsons, o uso da palavra neste título traz referências ao universo atual da família: a similaridade da palavra bard com o nome do nosso herói Bart é usada para fazer referência ao musical hip-hop "Do the bartman (1990)", interpretado por Bart na escola em um episódio anterior do próprio seriado.

Como Anderegg observou (2000, p. 157), as peças de Shakespeare precisam apenas do espaço vazio do palco e não dependem da montagem de ambientes específicos; não necessitam do 'realismo' do cinema, com seus cenários detalhados e visualmente expressivos. Neste ponto, a representação de The Simpsons talvez esteja mais próxima de Shakespeare do que muitas das representações fílmicas de suas peças, pois, uma característica dos desenhos animados é que a imagem e a atuação dos personagens sempre ficam no primeiro plano, às vezes, ao ponto de excluírem quase que completamente o ambiente em que a história acontece.

Os produtores de Do the bard, man não vão tão longe, mas simplificam, até certo ponto, o cenário. $\mathrm{O}$ fato é que dois fatores fundamentais, referentes ao lugar e à época histórica não são especificados na obra de Shakespeare a não ser pelo título da peça e por certas referencias nos diálogos. Estes fatores recebem um tratamento visual sutil em The Simpsons: a época medieval é mostrada por rápidas tomadas panorâmicas do castelo e da sala do trono, além de ser indicada pela roupa dos personagens; e a localização geográfica na Dinamarca é referida pela placa DANES DO IT MELANCHOLY e pela presença inconfundível do estereotipado Viking na quarta cena. Shakespeare usou o fundo escandinavo não somente para acompanhar a história do texto de partida medieval em que ele se baseou, mas também para distanciar a luta dinástica da realidade inglesa (como ele fez também em Macbeth, locali- 
zada na Escócia) e para fazer piadas sobre a vizinha Inglaterra. Os roteiristas de Do the bard, man, provavelmente, mantiveram a referência a Dinamarca por esta aparecer, muitas vezes, associada ao nome Hamlet, mas também porque, na imaginação popular norte-americana, os nórdicos guardam uma imagem de violência, e até de melancolia, que se ajustaria à representação aqui analisada.

Evidentemente, dentro do projeto poético de The Simpsons, o ambiente na Dinamarca medieval parece não conflitar com a presença constante de anacronismos que têm a ver com o dia-a-dia da rotina daquela família norte-americana - o sweater, a etiqueta no frasco de veneno, this mess, que Marge tem que enfrenta, no final do episódio. São exatamente estes que fornecem elementos de efeito cômico pelo contraste com o enredo trágico de Shakespeare.

Excluindo a introdução e a conclusão, que acontecem na sala da família Simpson, a ação se desenvolve em seis cenas (comparadas com as vinte de Shakespeare), que desencadeiam a história da peça. Todas se realizam dentro do castelo.

(Introdução: Sala dos Simpsons)

1. Hamlet encontra o fantasma do pai;

2. O fantasma descreve seu envenenamento e usurpação pelo irmão Claudius;

3. O fantasma pede vingança;

4. A culpa de Claudius é revelada e Ophelia se enlouquece;

5. O conselheiro Polonius é assassinado;

6. A carnificina final encerra a ação dramática.

(Epílogo: Sala dos Simpsons)

Com exceção do item (5), estas cenas são apresentadas na mesma sequência, em Shakespeare e em The Simpsons. Também os mesmos personagens principais do texto de Shakespeare são mantidos, todos representados pela família de Homer e seus amigos. Existem apenas duas personagens importantes da peça de Shakespeare, que não aparecem em Do the bard, man: Horatio, amigo 
de Hamlet; e Fortinbras, príncipe de Noruega, que fecha a cortina no fim da peça. A função desses dois personagens seria transmitir à plateia informações complementares à história principal, sendo um artifício teatral desnecessário no caso do The Simpsons. Podemos dizer que Homer, na sua casa, exerce o mesmo papel de Fortinbras ao fechar o livro que tem nas mãos e fazer o comentário final.

O clima do episódio Do the bard, man é bem diferente da seriedade sombria do texto-fonte, concentrando-se The Simpsons em aspectos cômicos e até, por vezes, infantis. Propõe-se, assim, uma re-escritura abrangente na representação das personagens e da ação dramática. Homer, por exemplo, além de representar um rei tragicamente envenenado, continua sendo o homem guloso de sempre; Bart, Lisa e Ralph continuam crianças e não jovens adultos com visões mórbidas; e a vida doméstica da família Simpson gera muitas referências na representação da peça, em um exercício de intertextualidade em que o contemporâneo e o antigo dão as mãos.

Um exemplo notável de releitura proposta pelos novos roteiristas se encontra na maneira de tratar as mortes da última parte da peça, com uma cena que possui um comic effect dentro do gênero humorístico conhecido como slap-stick, tipo de representação cômica que deve muito à atuação de palhaços de circo, com uma pancadaria ao mesmo tempo engraçada e grotesca. Segue uma tabela, mostrando o tratamento dado por Shakespeare e pelos roteiristas de Do the bard, man. Percebe-se, de imediato, que a única morte tratada da mesma maneira nos dois textos é a do rei Claudius - a única fundamental para dar sequencia ao tema básico de vingança.

\begin{tabular}{|l|l|l|}
\hline PERSONAGEM & $\begin{array}{l}\text { Em SHAKESPEARE, } \\
\text { morreu }\end{array}$ & $\begin{array}{l}\text { Em THE SIMPSONS, } \\
\text { morreu }\end{array}$ \\
\hline $\begin{array}{l}\text { Rosenkrantz e } \\
\text { Guildenstern }\end{array}$ & $\begin{array}{l}\text { em uma viagem a In- } \\
\text { glaterra; não sabemos } \\
\text { como. }\end{array}$ & $\begin{array}{l}\text { na corte, por veneno, um } \\
\text { tocando no outro }\end{array}$ \\
\hline Queen & $\begin{array}{l}\text { tomando veneno, por } \\
\text { engano. }\end{array}$ & $\begin{array}{l}\text { tocando propositalmente } \\
\text { no veneno. }\end{array}$ \\
\hline
\end{tabular}




\begin{tabular}{|l|l|l|}
\hline Laertes & ferido por Hamlet. & $\begin{array}{l}\text { espetando-se, por idiot- } \\
\text { ice, com a espada enven- } \\
\text { enada. }\end{array}$ \\
\hline King Claudius & $\begin{array}{l}\text { assassinado por Ham- } \\
\text { let com uma espada } \\
\text { envenenada. }\end{array}$ & $\begin{array}{l}\text { assassinado por Hamlet } \\
\text { com uma espada enven- } \\
\text { enada.. }\end{array}$ \\
\hline Hamlet & $\begin{array}{l}\text { depois de ferido, be- } \\
\text { bendo mais veneno. }\end{array}$ & $\begin{array}{l}\text { escorregando no sangue } \\
\text { envenenado }\end{array}$ \\
\hline
\end{tabular}

Para reforçar ainda mais aspectos que indiciam a mão dos adaptadores americanos, é interessante observar que, segundo Elizabeth Ramos (2006), todas as tragédias de Shakespeare contêm a mesma série de temas. As peças sempre tratam de um herói da classe alta, que corre grande perigo, e tem um desenlace que tende ao caos e a uma conclusão triste. O enredo, por sua vez, gira em torno de um problema, quer seja uma injustiça ou qualquer outro fator que desencadeia a ação dramática, incluindo a queda do herói, o que leva à queda de todos. O herói sempre vive uma situação de conflito e tem seu blind spot, ou seja, um ponto cego que nem sempre lhe permite discernir a complexidade dos fatos em que se acha inserido. Todos esses elementos, tão evidentes na peça de Shakespeare marcam sua presença na adaptação dos Simpsons.

O leque das possíveis escolhas feitas por aqueles que recriam uma obra clássica é amplo e seria até possível imaginar adaptações de Hamlet, em outros desenhos animados, utilizando recursos diferentes e provocando tantos outros impactos bem diversos daqueles propostos pelos Simpsons. Mas a escolha principal, neste caso, parece ter sido manter o ambiente medieval e nórdico do texto de partida, assim superpondo os personagens de The Simpsons, do começo do século XXI, aos da época de Shakespeare. Tal escolha parece, então, ter determinado as várias linguagens utilizadas, na adaptação analisada.

Os Simpsons apresentam Hamlet expressando-se através da língua inglesa normalmente falada pelo norte-americano branco da classe média baixa, sem, porém, incluir muitas expressões idiomá- 
ticas ou gíria. As únicas incursões que mostram um registro fora do padrão simpsônico seriam: uma parelha rimada, proveniente da peça de Shakespeare (ver nota 3); a cantarola louca 'medieval' de Ophelia (hey na nonny, nonny hey nonny); a expressão, também do texto-fonte, murther most foul, pronunciada por Homer com um acento de Brooklyn (moither) para aumentar o efeito cômico; e a palavra bíblica Behold! usada por Homer no seu papel de fantasma. Consta, também, apenas um trocadilho, quando Claudius corrige poison (veneno) a poi, son, for the royal luau, usando termos bem conhecidos da cultura havaiana ${ }^{3}$.

No que ser refere à linguagem visual, na maioria dos desenhos animados, as expressões faciais são, pela natureza desta arte, muito limitados, e os gestos mais voltados para movimentos energéticos corporais. Assim, a narrativa depende de um intercâmbio entre diálogo e ação rápida, exatamente o que encontramos em Do the bard, man. Um aspecto interessante é a inclusão, sem comentários, de várias piadas visuais: a coroa de Hamlet no poste da sua cama, como se fosse um boné comum, por exemplo, e a etiqueta no frasco do veneno. Essas inclusões contribuem para o aspecto cômico e satírico da adaptação.

A presença de música em Do the bard, man é tão reduzida, que merece um pequeno comentário. Consiste somente de uns acordes típicos de suspense para marcar o aparecimento do fantasma; uns segundos de música de banda do tipo medieval, acompanhando uma tomada panorâmica da sala do trono; e a música-tema do filme Ghostbusters (Caça-fantasmas), ao final. Aqui se percebe outro ponto de contato entre a obra de Shakespeare e a animação - nenhum dos dois precisa mesmo de uma partitura para transmitir sua mensagem.

A 'moldura' da peça, criada pela sala dos Simpsons, teria produzido uma complexidade semiótica, sequer sonhada no texto de Shakespeare. Quando assistimos a peça Hamlet no teatro ou no cinema, estamos vendo atores da vida real, conhecidos ou desconhecidos, assumindo papéis de personagens fictícios. Em Do the bard, man, assistimos a criações fictícias, de personagens de animação assumindo papéis de outras criações. O efeito é de aproximar os 
Simpsons de Springfield a nós, a plateia, e, ao mesmo tempo, nos distanciar dos acontecimentos sangrentos da Dinamarca medieval.

A introdução do episódio, na sala de TV dos Simpsons, teria também, como possíveis objetivos, introduzir o tema principal, que é o assassinato de um pai, e descartar o aspecto de incesto entre mãe e filho. O epílogo também tem sua função, principalmente, a de crítica à peça, especialmente pela reação negativa de Bart e pela aprovação de Lisa. Além disso, considere-se que sempre houve divergências de opinião a respeito de Hamlet - existe e provavelmente existirá uma corrente que ache a peça enfadonha por ser longa e de difícil de compreensão. A nosso ver, a inclusão desta divergência nos diálogos do episódio da animação só aumenta o valor da adaptação e as declarações de Bart não deixam de confirmar a abordagem irônica, até mesmo irreverente da série.

Finalmente, ao analisar esta versão animada de Hamlet, pensou-se em construir um storyboard alternativo para Os Simpsons, que contemplasse certas cenas que tinham sido deixadas de fora pelo seu diretor. Os storyboards são ferramentas intermediárias bastante utilizadas no cinema, na publicidade e na animação. Na definição de Niemeyer (1997, p. 146) são “a representação gráfica de todas as cenas do roteiro (se possível). É como se o roteiro fosse transformado em uma história em quadrinhos." A nossa proposta seria a de criar um storyboard complementar ao trabalho dos roteiristas de Do the bard, man para "brincar" com as escolhas de outros possíveis adaptadores do texto fonte.

A recriação de Hamlet no mundo dos Simpsons não inclui o que, provavelmente, são os dois momentos mais famosos da peça na imaginação popular, representações pelas quais o personagem Hamlet é quase que universalmente reconhecido: o famoso solilóquio que começa To be or not to be, e a cena com os coveiros quando o herói pega uma caveira e pondera sobre a efemeridade da vida. O fato das duas cenas poderem ser tidas como mórbidas talvez expliquem, mas não justificam a sua ausência na animação comentada. Assim sendo, com o propósito de mostrar como seria viável incluir temas mais introspectivos, sem perder de vista o re- 
gistro necessário em qualquer apresentação de The Simpsons, foi desenvolvido um pequeno storyboard, abrangendo e unificando as duas cenas mencionadas. Foi convidado o artista plástico baiano Bruno Cardoso Seara para produzir os desenhos do storyboard, seguindo o roteiro proposto. A nova cena seria inserida depois da cena 3 e duraria aproximadamente 20 segundos $^{4}$.

\section{STORYBOARD}

Hamlet on castle battle-
ments, teeth chattering,
in sweater and scarf
this? To be or not to be
brave - for fat old dad?"


Legenda em português:

1. Hamlet no parapeito do catelo, com um traje pesado e echarpe, dentes batendo.

2. Hamlet: "Será que eu consigo fazer isso? Ser ou não ser corajoso - para aquele pai gordo?"

3. Hamlet percebe uma alcova, onde se vê uma caveira.

4. Hamlet pega a caveira e fala alto, consigo mesmo: "Meu Deus, é assim que todos nós terminamos, mesmo?"

5. A caveira pisca o olho (close-up)

6. Hamlet assustado (close-up)

7. Hamlet olha para um lado e para o outro: "Estou sem saída."

8. Hamlet recoloca a caveira na alcova, virada para o outro lado.

9. Hamlet sorri: "Quem sabe? Pode ainda jorrar muito sangue!".

Não obstante a exclusão das duas cenas importantes, o que chama atenção nesta adaptação é o cuidado dos roteiristas em incluir muitos índices do seu texto de partida, que teria normalmente a duração de quatro horas, em uma animação de apenas cinco minutos. Além disso, dentro da estética da série, teriam conseguido fazer referência a tantos elementos da vida dos Simpsons, articulando-os com o texto de Shakespeare. Se alguém indagar se foi mostrada a essência da peça, convém responder que não, pois se trata de uma tarefa impossível; o fato é que não se defende aqui uma visão essencialista da obra de arte, pois cabe a cada receptor do texto fazer a sua própria interpretação, descobrir traços e diferentes abordagens diferentes, especialmente em uma peça tão complexa como essa. Então, pode a animação ser considerada um fracasso? Com certeza que não, apesar da opinião de Bart, pois a recriação cumpriu a função de divertir, informar e comentar fatos do polo de partida e do polo de chegada. Acreditamos que Do the bard, man poderia ser visto como um "petisco" ou um pequeno "tira-gosto" dessa obra-prima de Shakespeare. 


\section{APÊNDICE}

\section{TRANSCRIÇÃO DO EPISÓDIO EM INGLÊS E RESPECTIVA TRADUÇÃO PARA O PORTUGUÊS}

Do the bard, man.

Transcrição.

Introduction: The Simpsons' living room.

Homer (reading to his children) Our next story is Hamlet by William Shakespeare.

Bart Dad, these old stories can't compare with our modern superwriters. Stephen Bochco ${ }^{5}$ could kick Shakespeare's ass.

Lisa Bart, this guy's more interesting than you think. Starts with Hamlet's father getting murdered.

Bart Cool. Does he get to marry his mom?

Homer I dunno, but that would be hot. Once upon a time there was a young prince of Denmark. . .

Scene 1: Hamlet's bedroom in the castle.

(Hamlet in bed. Poster on wall showing 'DANES DO IT MELANCHOLY'. Banner showing 'FEUDALISM')

Ghost (Homer) Hamlet, avenge me!

Hamlet (Bart) Dad?

Ghost Yes, I have returned from the dead.

Hamlet Looks like you've returned from the buffet.

Ghost Why you little. . . .!

Hamlet (laughs)

Ghost My son, I have some shocking news. I was murdered, murdered I tells ya.

Hamlet Really? 


\section{Scene 2: (Flashback) Ghost when king, on throne}

Ghost (voice over) Behold, as I slept, your uncle Claudius poired poison in my ear, moidered most foul, so he could marry your mother and become the king.

\section{Scene 3: Hamlet 's bedroom again}

Hamlet Yeah, that was quite a weekend.

Ghost Now you must avenge me. AVENGE ME.

Hamlet How?

Ghost I dunno. Surprise me. SURPRISE ME. (passes through wall)

Hamlet Could that fat ghost be telling the truth? First I've got to get Uncle Claudius to confess, then I've got to kill him.

Ghost (reappears through wall) It's cold outside. You'll need a sweater. A SWEATER.

\section{Scene 4: Throne-room at the Castle}

(Panorama of castle and throne-room. Jester on stage. Audience at tables. King and Queen on thrones.)

Jester (Krusty) And if your idea of a first date is burning down her village, you just might be a VIKING!

Viking That's what I get for sitting up front, eh? (sets fire to neighbours' table and abducts two women)

Queen (Marge) I love these jesters. They're exactly what I need to forget about my first husband.

King (Moe) Yeah, I really miss the old guy. It was all I could do to put on his jewels, and score with his wife every night. (To Hamlet) How you doing kid? Nice to see you. 
Jester Now we would like to warn you our performances tend to make audience members blurt out hidden secrets.

King Oh boy!

Hamlet Aha! Methinks the play's the thing wherein I'll catch the conscience of the king.

King Catch my conscience? What?

Hamlet You're not supposed to hear me! That's a soliloquy!

King Okay, well I'll do a soliloquy too. Note to self - kill that kid!

Jester Okay, we gonna open it up with a little improv. Somebody shout out a location.

Hamlet This castle.

Jester Okay, how about an occupation?

Hamlet Usurper of the throne.

Jester I think I heard 'usurper of the throne'. Now finally I need an object.

Hamlet Ear poison.

King (to Queen) Hey, ya, do you have diarrhea? I have diarrhea. Queen Sit down.

(Bottle showing: EAR POISON - DO NOT GET IN EYES. Poisoning is acted out on stage)

King Wait a minute. I didn't use that much poison. I di- I mean. I didn't use that much poi, son... at the royal luau.

Hamlet (shocked) Daddy, it's true, Uncle Claudius murdered you. Ophelia (Lisa) Oh great, now Hamlet's acting crazy. Well, nobody out-crazes Ophelia.

Hey nonny with a hoo an' a hah, an' a nonny nonny hey... (runs over the tables and jumps out of the window)

\section{Scene 5: Queen's bed-chamber}

(Queen in bed. Hamlet enters running with sword) 
Queen What I tell you about running with swords?

Hamlet Someone's behind the curtain. It could be Claudius. Only one way to find out.

(stabs curtain) Polonius! What are you doing behind the curtain?

Polonius (Wiggum) I hide behind curtains 'cos I have a fear of getting stabbed.

Laertes (Ralph) Daddy's stomach is crying!

Polonius Laertes, you gotta do a special big boy job for Daddy. I need you to avenge my death.

Laertes I like revenging.

\section{Scene 6: Throne room}

Laertes I'm going to kill Hamlet. Here's my mad face.

King Cute kid. But just in case you don't kill Hamlet, I put some poison on the food, on the drapes, even on Rosencarl and Guildenlenny here.

Rosencarl/Guildenlenny (Carl/Lenny)

If Hamlet touches either of us, he's dead! (touch each other and die)

King Hamlet, you know the rules - Laertes here gets one practice stab.

Laertes Oh boy! (stabs himself and dies)

King Oh boy, did I bet on the wrong horse!

Hamlet Now there's nothing to stop me from getting my vengeance!

King You're sure you don't want a nice piece of fish or to finger the drapes a little?

Hamlet This ends here! (stabs King with sword)

King Remember me as a peace-maker. (dies)

Hamlet And now to celebrate life! Whoa, bloody floor! (dies)

Queen No way I'm cleaning up this mess. (touches head with poisoned arm and dies) 


\section{Epilogue: The Simpsons' living room}

Lisa And that's the greatest scene ever written

Bart Are you crazy? I can't believe a play where every character is murdered could be so boring.

Homer Son, it's not only a great play but also became a great movie, called -

Ghostbusters! (all dance)

\section{TRADUÇÃO NOSSA:}

\section{Introdução: Na sala dos Simpsons}

Homero (lendo para os filhos) Nossa próxima história é Hamlet de Shakespeare.

Bart Pai, essas historias antigas nem se comparam com as dos super escritores de hoje.

Janete Clair daria uma surra em Shakespeare.

Lisa Bart, esse cara é bem mais interessante. A história começa com o assassinato do pai de Hamlet.

Bart Legal. Ele chega a casar com a mãe?

Homero Não sei - puxa - seria excitante! Era uma vez um príncipe da Dinamarca. . .

\section{Cena 1: No quarto de Hamlet no castelo}

(Hamlet na cama. Na parede, um quadro com o texto OS DINAMARQUESES O TORNAM MELANCÓLICO' e uma bandeira com a palavra FEUDALISMO)

Fantasma (Homero) Hamlet, vingue-me!

Hamlet (Bart) Pai?

Fantasma Sou eu. Voltei dos mortos.

Hamlet Parece que voltou da lanchonete. 
Fantasma Seu pestinha. . .

Hamlet (risada)

Fantasma Meu filho, tenho novidades que vão deixar você chocado Fui assassinado.

ASSASSASSINADO.

Hamlet É mesmo?

Cena 2: (Em retrospecto) $O$ fantasma vê-se quando era rei, no trono

(Descreve o envenenamento, voice over)

Fantasma Preste atenção! Quando eu dormia, seu tio Cláudio botou veneno no meu ouvido, assassinato torpe, para ele poder casar com sua mãe e tornar-se o rei.

\section{Cena 3: No quarto de Hamlet}

Hamlet Que farra legal!

Fantasma Agora você tem que me vingar. ME VINGAR.

Hamlet Como?

Fantasma Sei lá. Surpreenda-me. SURPREENDA-ME. (passa pela parede)

Hamlet Será que este gorducho está contando a verdade? Primeiro, tenho que fazer com que meu tio Cláudio confesse. Depois, matar.

Fantasma (reaparece, passando pela parede) Faz frio lá fora, bote uma blusa. UMA BLUSA.

\section{Cena 4: Na sala do trono do castelo}

(Tomada panorâmica do castelo e da sala do trono. Jester no palco. Platéia em mesas pequenas. Rei e Rainha nos seus tronos)

Bobo (Krusty) E se, logo na sua primeira saída, você quiser incendiar 
a casa dela - será que você é - um VIKING!

Viking $\quad \mathbf{E}$ isso que dá eu sentar na frente, não é? (acende a mesa vizinha e rapta duas moças)

Rainha (Marge) Adoro esses bobos. Exatamente o que eu precisava para esquecer meu primeiro marido.

Rei (Moe) É, sinto tantas saudades do velho. Mal consegui pegar as jóias dele e dar conta da esposa dele todas as noites. (riso sardônico) (a Hamlet) Como vai, menino? Prazer em vê-lo.

Bobo Agora, queremos avisar que, às vezes, nossas representações fazem com que a platéia revele seus segredos.

Rei Meu Deus!

Hamlet Olhe só!

A peça o lasso há de bem ser

Com que a consciência do rei eu vou prender ${ }^{6}$.

Rei Prender minha consciência? O quê?

Hamlet Não era para você ouvir isso - é um solilóquio.

Rei Tudo bem, faço um solilóquio também. Registre aí: mate este menino!

Bobo Gente, vamos improvisar um pouco. Qualquer um - diga um lugar.

Hamlet Este castelo.

Bobo Ok, agora, uma profissão.

Hamlet Usurpador do trono.

Bobo Ouvi 'usurpador do trono', certo? Agora, para terminar, precisamos de um objeto.

Hamlet Veneno no ouvido.

Rei (a Rainha) Oi, você tem diarreia? Eu tenho diarreia.

Rainha Sente-se.

(Frasco com etiqueta: VENENO NO OUVIDO - EVITE CONTATO COM OS OLHOS. O envenenamento é apresentado no palco.)

Rei Espera ai! Não usei tanto tóxico - quero dizer, tanto toucinho, na feijoada real.

Hamlet (chocado) Papai, é verdade. Tio Cláudio matou você!

Ofélia (Lisa) Ótimo - agora, Hamlet está ficando doido. Ninguém pode 
ficar mais doida do que eu - rey nony nony e um ro e um ra, e um nony nony rey (corre em cima das mesas e pula da janela)

\section{Cena 5: Quarto da Rainha}

(Rainha na cama. Hamlet entra correndo, espada na mão)

Rainha Hamlet, já falei para não correr com a espada.

Hamlet Tem alguém atrás da cortina, será que é Cláudio? Eu tenho como saber.

(fura a cortina com a espada) Polônio! O que está fazendo atrás da cortina?

Polônio (Wiggum) Estou aqui porque tenho medo de ser espetado.

Laerte (Ralph) A barriga de papai está chorando!

Polônio Laerte, você tem que fazer para o papai uma coisa que gente grande faz. Você tem que vingar minha morte!

Laerte Eu adoro vingança.

\section{Cena 6: Sala do trono}

Laerte Vou matar Hamlet. Olhe só minha cara de raiva.

Rei Bom menino. Mas, se por acaso, não conseguir matá-lo, eu botei veneno na comida, nas cortinas, até em Rosachoque e Guirlandona aqui.

Rosachoque e Guirlandona (Carl e Lenny)

Se Hamlet tocar em qualquer um, já morreu! (tocam-se e morrem)

Rei Hamlet, você conhece as regras. Laerte tem direto a um ensaio.

Laerte Bacana! (se espeta e morre)

Rei Meu Deus, apostei no cavalo errado!

Hamlet Agora não tem nada que detenha a minha vingança!

Rei Com certeza, não quer comer um peixinho ou tocar nas cortinas, um pouco? 


$\begin{array}{ll}\text { Hamlet } & \text { Isso termina aqui! (espeta o Rei) } \\ \text { Rei } & \text { Lembrem de mim como um pacificador. (morre) } \\ \text { Hamlet } & \begin{array}{l}\text { Agora, para desfrutar da vida! Ah, chão sangrento. } \\ \text { (escorrega e morre) }\end{array} \\ \text { Rainha } & \text { (entrando) Não vou conseguir arrumar essa bagunça! } \\ & \text { (bate na cabeça com uma arma envenenada e morre) }\end{array}$

\section{Epílogo: Na sala dos Simpsons}

$\begin{array}{ll}\text { Lisa } & \text { Aí está a melhor encenação de todos os tempos! } \\ \text { Bart } & \text { Endoidou? Não consigo acreditar que uma peça em que } \\ & \text { todos são assassinados possa ser tão chata. } \\ \text { Homero } & \text { Filho, não é somente uma grande peça, também virou um } \\ & \text { grande filme chamado - Os Caça-fantasmas! (a família } \\ & \text { toda dança ao som da música do filme) }\end{array}$

\section{Notas}

1. Uma transcrição do episódio inteiro e uma tradução para o português se encontram no Apêndice deste ensaio

2. A única outra referência aos solilóquios é a citação direta, também na voz de Bart, da parelha rimada, que termina o solilóquio

3. Na versão portuguesa da transcrição, criamos um trocadilho em português ver Apêndice.

$O$ what a rogue and peasant slave am I:

The play's the thing

Wherein I'll catch the conscience of the king. 
4. A referida proposta da inclusão de um storyboard complementar para os Simpsons foi desenvolvida como exercício de criatividade pelos alunos do curso de tradução intersemiótica ministrado na Pós-Graduação da UFBA em 2006, tendo a aluna Marisa Medeiros Seara tomado a iniciativa de convidar um artista plástico para ilustrar os diálogos produzidos.

5. Steven Bochco (1943- ) escritor e produtor de TV e autor de diversos seriados de sucesso: Hill Street Blues, L.A. Law e NYPD Blue.

6. Tradução da parelha rimada cortesia Luiz Angélico da COSTA (2006)

\section{Referências}

ANDEREGG, Michael. Welles/Shakespeare/Film. In: NAREMORE, James (Ed.). Film Adaptation. Nova Jersey: Rutgers, 2000.

BLOOM, Harold. Hamlet, poema ilimitado. Rio de Janeiro: Objetiva, 2004.

COSTA, Luiz Angélico da. O processo de recriação de 4 solilóquios de Hamlet. Palestra, Instituto de Letras, UFBA Salvador, 2006.

DO THE BARD, MAN. 2002. Parte do Episódio: Tales from the Public Domain. The Simpson's 13th season, televisado nos Estados Unidos em 17 de março de 2002.

GENETTE, Gerard. Palimpsests: Literature in the Second Degree. Lincoln e London: University of Nebraska Press, 1997. (Tradução inglesa por Newman e Doubinsky do original francês Palimpsestes: La littérature au second degré. Paris: Seuil, 1982.) 
HUTCHEON, Linda. A Theory of Adaptation. Nova York: Routledge, 2006.

NIEMEYER FILHO, Aloysio. Ver e ouvir. Brasília: UF Brasília, 1997.

RAMOS, Elizabeth. [As tragédias de Shakespeare]. Palestra no Instituto de Letras, Universidade Federal da Bahia- UFBA. Salvador, 31 ago. 2006.

SHAKESPEARE, William. Hamlet, Prince of Denmark (1601-1602) In:

The Complete Works of William Shakespeare. Londres: Oxford UP, 1959.

Recebido em 15/01/2014 Aceito em 29/04/2014 
